Volume 19, No 2 International Journal of Radiation Research, April 2021

\title{
Evaluation of the oxidative stress in liver of mice vaccinated with gamma radiation-attenuated Toxoplasma gondii
}

\author{
E.N. Hafez ${ }^{*}$, R.M. Ebrahim¹, A.M. Barakat ${ }^{2}$ \\ ${ }^{1}$ Department of Health Radiation Research, National Center for Radiation Research and Technology (NCRRT), \\ Egyptian Atomic Energy Authority, Cairo, Egypt \\ ${ }^{2}$ Department of Zoonotic diseases, National Research Centre, Cairo, Egypt
}

\section{- Original article}

\section{*Corresponding authors: \\ Eman Naser Hafez, PhD., \\ E-mail: \\ eman_naser612@hotmail.com}

Revised: April 2020

Accepted: June 2020

Int. J. Radiat. Res., April 2021; 19(2): $339-347$

DOI: $10.29252 /$ ijrr.19.2.339

\begin{abstract}
Background: Researches on attenuated Toxoplasma gondii vaccine have shown its protective effect against challenged infection in addition to its therapeutic rather than preventative activity against some autoimmune and malignant diseases. Rise in oxidative stress is one of the most common signs of toxoplasmosis; hence this study aims to determine local oxidative stress on hepatocytes as well as associated immune variations in mice vaccinated with gamma radiation-attenuated Toxoplasma gondii. Materials and Methods: Thirty female Swiss albino mice are divided into: normal control; mice infected with $T$. gondii cysts (infected control) and mice vaccinated with the same infective dose attenuated with $0.4 \mathrm{KGy}$ of gamma radiation (vaccinated group). Results: Hepatic superoxide dismutase (SOD), Malondialdehyde (MDA) and inducible nitric oxidase (INOs) levels were significantly increased with a significant decrease in reduced glutathione (GSH) in liver tissues of infected control mice. Besides, serum levels of interlekin-10 (IL-10) and tumor necrosis factor- $\alpha$ (TNF- $\alpha$ ) were significantly elevated. Moreover, histopathological examinations revealed distinct alterations with decreased nuclear expression of DNA in hepatocytes. Conversely, vaccinated group exhibited an improvement in oxidative stress and elevation in nuclear expression of DNA in hepatocytes collimated with an amelioration of the histopathological alterations. Furthermore, reduced serum IL-10 and TNF- $\alpha$ level were detected. Conclusion: It is concluded that attenuation of Toxoplasma gondii with gamma radiation exerted protective effect in liver tissues against oxidative stress and DNA damages of hepatocytes with an improvement of host's immune response.
\end{abstract}

Keywords: Toxoplasma gondii, Gamma radiation, Liver, Oxidative stress, DNA damage.

\section{INTRODUCTION}

Toxoplasma gondii is a zoonotic protozoan parasite that can cause morbidity and mortality in humans as well as in domestic animals. Infection occurs as a result of drinking or eating vegetables washed with water from faucets $(1,2)$.

In acute infection, the parasite metabolizes glucose for energy production and its growth, so oxidative stress and free radicals production occur (3). Oxidizing radicals leading to pathological processes can directly damage those free radicals. Immune system is stimulated resulting in defense mechanisms to limit free radical production. These mechanisms employ antioxidant enzymes as SOD and GSH which are inducible by oxidant stress (4).

SOD is a first line of defense antioxidant, as it prevents formation of new free radical and converts the existing into less harmful 
molecules. It catalysis the dismutation of superoxide radical into hydrogen peroxide $\left(\mathrm{H}_{2}\right.$ $\mathrm{O}_{2}$ ) and molecular oxygen participates in deletion and neutralization of toxic reactive oxygen species (ROS). Glutathione is the most abundant non-protein thiol source in the cell. It acts as a substrate for several enzymes, including glutathione peroxidase. It plays an important role in counteracting oxidative damage and maintaining cell health (5-7).

Lipid peroxidation is a degenerative process that alters the fluidity of biological membranes and then causes cell degradation. It causes production and propagation of free radical reactions that involve membrane polyunsaturated fatty acids and damages the enzyme system as well as nuclear DNA (8).

Inducible nitric oxidase is an inducible immune inflammatory factor expressed in response to interferon gamma (IFN- $\gamma$ ) which is an important cytokine that eliminate intracellular Toxoplasma gondii. This enzyme can be found in activated macrophages and hepatocytes that generate NO during infection and thereby contributes to control replication or killing of pathogens. It was identified as an anti-Toxoplasma host factor in mice and its genetic deletion or inhibition from the beginning of infection increased the number of $T$. gondii cysts in the brain (9-11).

Host's immune reaction against toxoplasmosis depends on cellular immunity through secretion of cytokines such as interleukin-12 (IL-12), IFN- $\gamma$, IL-10 and TNF- $\alpha$ which are key regulator of immune response cascade (12). However, T. gondii can manipulate this host immunity through deregulation of signaling pathways and controlling host gene transcription by the parasite effector proteins secreted from rhoptries (13). It was reported that TNF- $\alpha$ is a proinflammatory cytokine involved in mediating the pathology and makes up the acute phase reaction of toxoplasmosis. While IL-10 counters the harmful inflammatory effect as a result of type-1 immune response $(14,15)$.

Vaccination of animals with gamma radiation -attenuated Toxoplasma not only protects against challenged infection but it circumvents the danger of un-irradiated vaccine that remains life-threatening (16). Non replicating Toxoplasma strain is capable of preventing development of some autoimmune diseases as lupus nephritis and arthritis in experimental animals $(17,18)$. Furthermore, its antitumor activity against ovarian carcinoma, leukemia, sarcoma, Lewis lung and melanoma had been demonstrated (1921).

Attenuation of $T$. gondii with radiation induces marked morphological changes such as decrease in rhoptries, disappearance of golgi complex and mitochondria in addition to decreased number of electron dense granules. Severe damage to various intracellular organelles including the nucleus occurs so the parasites lose their reproductive ability while still maintaining immunogenicity (22).

Based on previous studies that reported the immunoprotective effect of gamma radiation-attenuated Toxoplasma vaccine (23) and our recent model demonstrated that using this vaccine produced immune protection against ovarian infiltration in Ehrlich ascites carcinoma-bearing mice (24), this study is undertaken to spot the light on the effect of vaccination on hepatic oxidative stress and the host's immune response.

\section{MATERIALS AND METHODS}

Thirty Swiss albino female mice 8-10 weeks-old with 22-25g weight were used in the current study. They were obtained from the breeding unit of the Egyptian Organization for Biological Products and Vaccines, housed in cages (5 animals/cage) and maintained on a commercial standard pellet diet and tap water ad libitum. They were also maintained under standard environmental conditions, continually monitored for survival and clinical condition till the end of experiment. Low virulence T. gondii Me49 cysts, which were harvested from the brain of mice that had been intraperitonealy inoculated according to Atmaca et al. (25) were used to induce acute infection. Ten mice were orally infected with ten T.gondii cysts (20) as infected group. The second group was vaccinated with the same dose of T. gondii cysts 
that were exposed to attenuating dose (0.4 KGy) of gamma radiation (26) as vaccinated group and the third group was used as normal control. The study was conducted in the National Center for Radiation Research and Technology (NCRRT) Cairo, Egypt and the animal care was taken in accordance with the recommendations of the Scientific Research Ethical Committee.

Three weeks post infection, the experiment was terminated by anaesthetizing the animals with ether. Liver tissue samples were collected half of them were fixed in $10 \%$ phosphate buffered formalin ( $\mathrm{pH}$ 7.4), embedded in paraffin wax and sections of 5-micrometer thickness were cut. Slides were stained with Haematoxylin and eosin for histological examination (27) and with Feulgen's stain for histochemical demonstration of DNA (28). The other half of liver tissues of each group were weighted and placed on PBS buffer (1:1) and subsequent homogenization was done then centrifuged at $4000 \mathrm{~g}$ for 20 minutes. The supernatant was collected for biochemical study. Blood samples were collected, centrifuged and sera were separated for determination of TNF- $\alpha$ and IL-10.

Chemicals and reagent in this study were obtained from Sigma-Aldrich Chemical Co., St. (Louis, MO, USA). All ELISA assays for SOD, GSH, MDA and iNOs levels were performed according to the manufacturer's instructions of commercial kit (Bio-diagnostic, Dokki, Giza, Egypt) and serum cytokines according to MyBioSource kit (Glory Science Co., Ltd, USA).

\section{Determination of SOD activity}

The assay for super oxide dismutase activity involved inhibition of nitroblue tetrazolium (NBT) reduction, with xanthine oxidase. One unit SOD was defined as the amount of protein that inhibits the rate of NBT reduction by $50 \%$. It was determined at $560 \mathrm{~nm}$ and expressed as $\mathrm{U} / \mathrm{g}$ (30).

\section{Determination of GSH}

Reduced glutathione was determined as previously described by Beutler (31). The method based on the reduction of 5.5- dithiobis-2nitrobenzoic acid (DTNB) with glutathione to produce a yellow compound. The reduced chromogen was directly proportional to GSH concentration and its absorbance was determined at $405 \mathrm{~nm}$ and expressed as $\mathrm{mmol} / \mathrm{g}$ tissue.

\section{Determination of lipid peroxidation}

Levels of thiobarbituric acid reacting substance (TBARS) as a marker of lipid peroxidation were determined according to the method described by Ohkawa et al. (29). The formation of pink color, as a result of the reaction was measured at $535 \mathrm{~nm}$ and expressed as $\mathrm{nmol} / \mathrm{g}$ liver tissue.

\section{Inducible Nitric oxidase measurement}

INOs in the crude liver tissue homogenate was determined using a commercial kit (Bio diagnostic, Egypt).

\section{Determination of serum TNF- $\alpha$ and IL-10}

Serum levels of TNF- $\alpha$ and IL-10 were assayed by Enzyme linked-Immunosorbent Assay (ELISA) using the MyBioSource kit. Measurements were done according to methods of Sutterwala et al. (32).

\section{Statistical analysis}

All data were expressed as mean \pm SE (standard error). Data were assessed by using a one- way ANOVA using SPSS 15.0 program and $\mathrm{p}<0.05$ was considered statistically significant.

\section{RESULTS}

\section{Histopathological findings}

Figure 1 represents H\&E stained liver sections where normal control group exhibited average central veins surrounded by hepatocytes arranged in single-cell cords with intervening blood sinusoids, and normal portal tracts with average bile ducts and portal veins (figure 1, a, a1). Liver sections of infected control group showed portal tract with markedly dilated portal veins and inflammatory cellular infiltration around the portal area. Dilated central vein with detached lining and peri-venular inflammatory infiltrate can be also 
detected (figure 1, b, b1). Vaccinated group revealed average central veins and mild intra-lobular inflammatory infiltrate. Also, dilated congested portal veins with average hepatocytes in peri-portal area were clearly seen (figure 1, c, c1).

\section{Histochemical expression of DNA Feulgen's stain}

Expression of hepatic DNA content was shown in figure 2, table 1. Normal group revealed marked positivity for Feulgen (14.5 \pm 1.2 ), average DNA distribution and intact nuclear membrane in most of hepatocytes. Toxoplasma-infected group revealed mild positivity for Feulgen $(2.9 \pm 0.6)$ with loss of nuclear membrane in most of hepatocyte nuclei in peri-venular area and high significant decrease $(P<0.001)$ compared to normal control. Moderate positivity for Feulgen $(9 \pm 0.8)$ with few reduction of DNA in hepatocyte nuclei and significant decrease was detected in vaccinated group compared to normal $(\mathrm{P}<0.01)$ and high significant increase compared to infected group $(\mathrm{P}<0.001)$.

Biochemical analysis of oxidative stress in liver tissues of infected control group showed significant increase in SOD levels compared to normal control while vaccinated mice group revealed significant decrease compared to infected control (figure 3a). GSH levels were significantly decreased in infected control mice group compared to normal control however; their levels were significantly increased in vaccinated group (figure $3 \mathrm{~b}$ ). A significant increase in MDA was detected in infected control group compared to the normal group on contrary to vaccinated group showed a significant decreased compared to infected control one (figure $3 c)(P<0.001)$.

Regarding INOs, the mean \pm SE was $94.8 \pm 3.8$ in infected group while it was $43.6 \pm 0.9$ in normal control with high significant increase $(\mathrm{P}<0.001)$. In vaccinated group it was $64.2 \pm 1.4$ showing high significant decrease versus infected control group $(\mathrm{P}<0.001)$ and significant increase $(\mathrm{P}<0.01)$ versus normal one (table 1$)$.

To gain insight into the immunological mode of action of irradiated T. gondii, we next examined the influence of vaccination on the serum inflammatory cytokines (table 2). TNF- $\alpha$ and IL-10 levels were $42.3 \pm 0.8$ and $67.8 \pm 4.9$ respectively in infected control group while they were $9.8 \pm 0.5$ and $140.2 \pm 3$ respectively in normal control with high significant increase as $\mathrm{P}<0.001$. On contrary, they were $18.4 \pm 0.7$ and $409.2 \pm 5.3$ respectively in vaccinated group showing high significant decrease $(\mathrm{P}<0.001)$ versus infected control one.

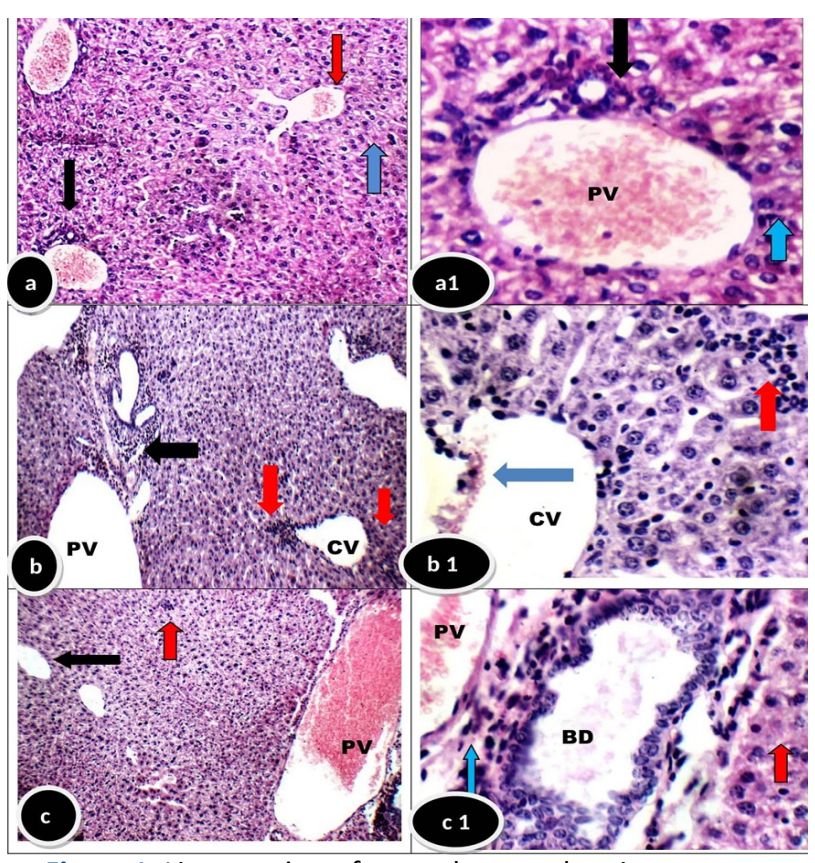

Figure 1. Liver section of normal group showing average portal tract with average portal vein (PV), average bile duct (black arrow), average central vein (red arrow) and average hepatocytes (blue arrow) (a, a1). Infected group showed expanded portal tract with portal inflammatory infiltrate (black arrow) and markedly dilated portal veins (PV). Dilated central vein (CV) with detached lining (blue arrow) and peri-venular inflammatory infiltrate (red arrow) can be detected (b, b1). Vaccinated-group showed portal tract with dilated congested portal vein (PV), average central veins (black arrow), and mild intra-lobular inflammatory infiltrate (blue arrow), markedly dilated portal vein (PV), and average hepatocytes in peri-portal area (red arrow) (c, c1) (a-c X200, a1-c1 X400).

Table 1. Expression of INOs and DNA in hepatocytes of experimental groups.

\begin{tabular}{|c|c|c|}
\hline Groups Parameters & INOs & DNA \\
\hline Normal control & $43.6 \pm 0.9$ & $14.5 \pm 1.2$ \\
\hline Infected control & $94.8 \pm 3.8^{* *}$ & $2.9 \pm 0.6^{* *}$ \\
\hline Vaccinated group & $64.2 \pm 1.4^{*,++}$ & $9 \pm 0.8^{*},++$ \\
\hline
\end{tabular}

Data are expressed as mean \pm SE.

* Significant compared to normal group $P<0.01$.

$* *$ High significant compared to normal group $\mathrm{P}<0.001$

++ High significant compared to infected group $\mathrm{P}<0.001$. Int. J. Radiat. Res., Vol. 19 No. 2, April 2021 
Figure 2. Normal control group showing marked positivity for Feulgen (+++) with average DNA distribution in most of rounded hepatocyte nuclei with intact nuclear membrane in peri-venular area (red arrows) (a, a1). Infected group showed mild positivity for Feulgen (+) with marked reduction of DNA and loss of nuclear membrane in most of hepatocyte nuclei in peri-venular area (red arrows) (b, b1). Vaccinated group showed moderate positivity for Feulgen (++) with reduction of DNA in few of hepatocyte nuclei with loss of nuclear membrane in peri-portal area (red arrows) (c, c1) (Feulgen stain a-c X 400, a1-c1X1000).

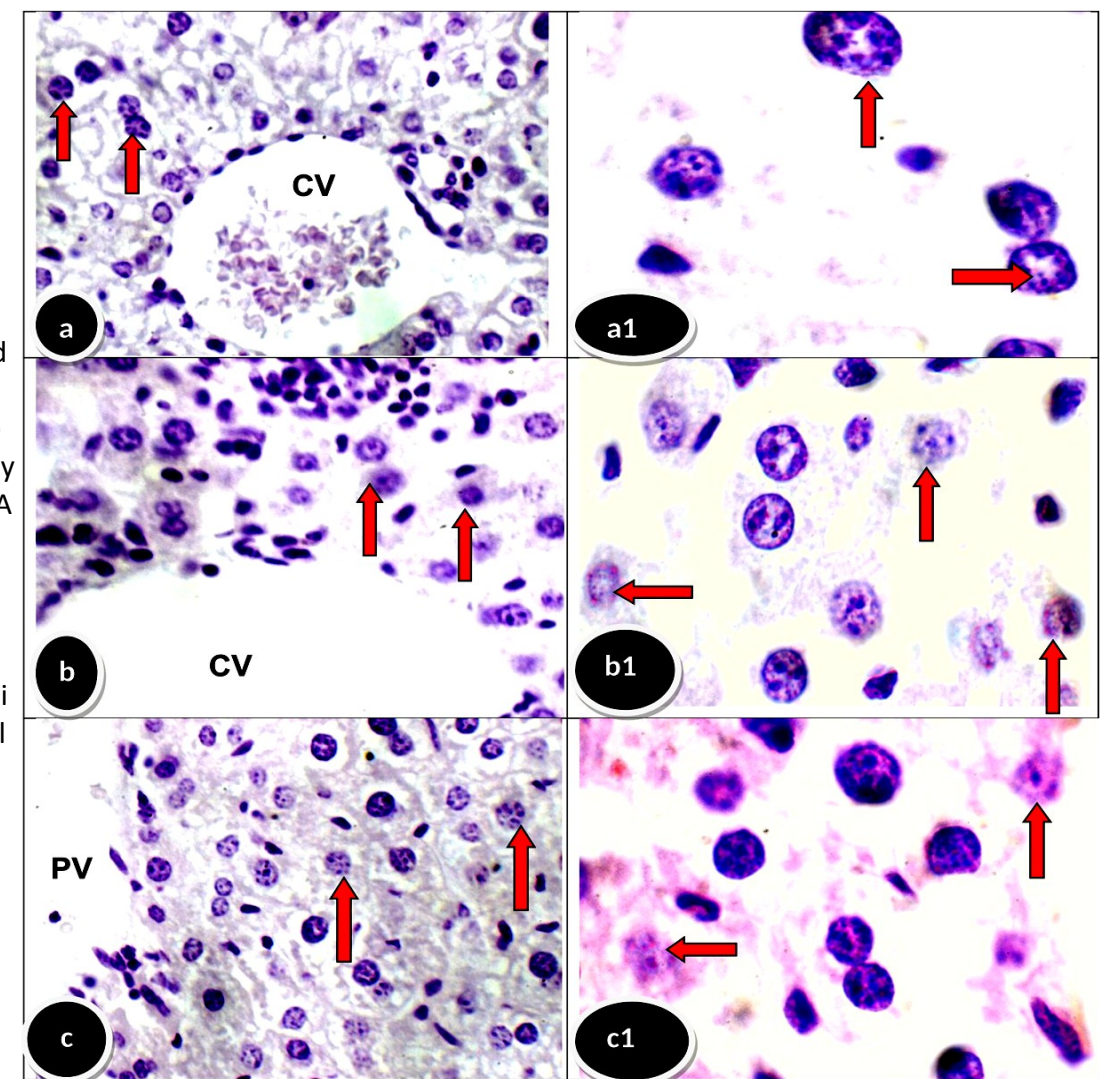

a

a
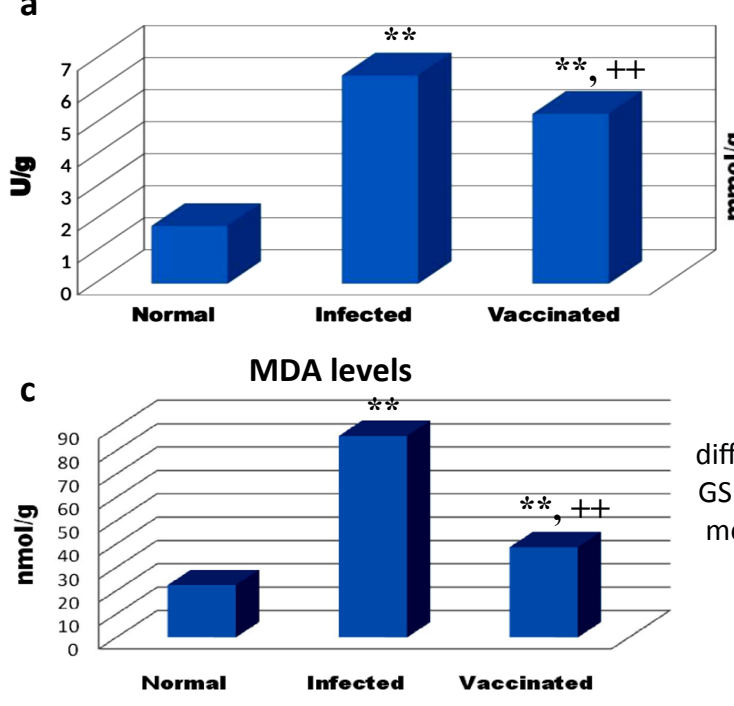

b

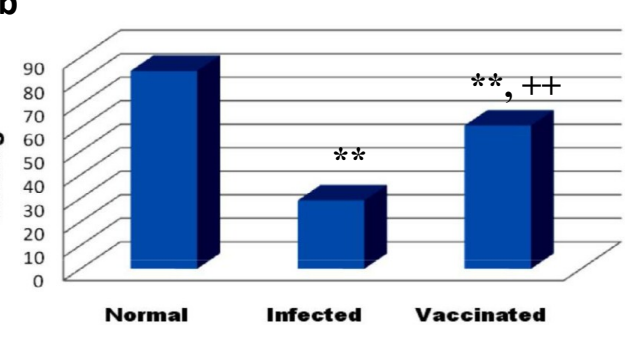

Figure 3. Levels of oxidative stress markers in different studied groups. (a) level of SOD, (b) level of GSH and (c) level of MAD. Each value represents the mean \pm S.E. ${ }^{* *}$ Significant difference versus normal control group. ++ Significant difference versus infected control group at $\mathrm{P}<0.001$.

\begin{tabular}{|c|c|c|c|}
\hline \multirow{4}{*}{$\begin{array}{l}\text { Table 2. Mean } \pm \text { SE of IL-10 and TNF- } \alpha \\
\text { in the sera of experimental mice. } \\
\text { Data are expressed as mean } \pm \text { SE. } \\
\text { * Significant compared to normal group. } \\
\text { + Significant compared to infected group. } \\
P<0.001\end{array}$} & Parameters & TNF- $\alpha \mathrm{pg} / \mathrm{ml}$ & IL-10 pg/ml \\
\hline & Normal control & $9.8 \pm 0.5$ & $140.2 \pm 3$ \\
\hline & Infected control & $42.3 \pm 0.8^{*}$ & $678.2 \pm 4.9^{*}$ \\
\hline & Vaccinated group & $18.4 \pm 0.7^{*},+$ & $409.2 \pm 5.3^{*,+}$ \\
\hline
\end{tabular}

Int. J. Radiat. Res., Vol. 19 No. 2, April 2021 


\section{DISCUSSION}

Most of previous studies have focused on the attenuation of Toxoplasmagondii by radiations that help maintaining their integrity, antigenicity while increasing immunogenicity so eliciting an immune-protective effect. For instance, it has been previously reported that vaccination with gamma radiation-attenuated Toxoplasma tachyzoites resulted in an amelioration of histopathological changes in liver, lung, kidney, spleen and testis of experimentally infected mice (22). Recently, using gamma radiation-attenuated T. gondii cysts vaccine has demonstrated immune protection against ovarian infiltration in mice-bearing Ehrlich ascites carcinoma (24). As one of the most common signs of toxoplasmosis is a rise of hepatic oxidative stress, hence the aim of the present study is to determine the impact of gamma irradiated Toxoplasma cyst vaccine on hepatic oxidative stress, INOs and immune response in mice.

The data of this study demonstrated a significant decrease level of GSH in infected group compared to normal. This is in agreement with previous reports that revealed a decrease of GSH and increase of GPX activity in different tissues of Toxoplasma-infected hosts (33-35). A significant increase of SOD in the infected group was noted, which is in accordance to the study of Turkoglu et al. (36) who reported an increase of SOD in liver tissues of the infected mice thirty days post infection. In the literature, SOD level was reported to be increased several weeks post -infection with other parasites as Fasciola hepatica, Trichinella spiralis, Schistosoma mansoni and Trypanosoma cruzi several weeks post-infection (37-39).

Lipid peroxidation, determined by MDA concentration, was significantly increased in infected group. In accordance of these results is the previous works which reported higher level of MDA in liver of infected rats $(33,36)$. Significant increase of INOS expression in hepatocytes was detected in our study. This is compatible with the previous study of Dincel and Atmaca (40) who reported a remarkable increase of it during $T$. gondii encephalitis in mice 74 days after inoculation. It was reported to be strongly stimulated by IFN- $\gamma$ produced by parasite-infected monocytes (41). In agreement to our results, another study reported a significant increase of hepatic lipid peroxidation and NO and decrease in GSH activity in liver homogenates of control infected group (42).

In Toxoplasma-vaccinated group, a high significant increase in GSH with decrease of SOD, MDA and INOs levels were detected compared to infected group. Similar to mice vaccinated with gamma radiation-attenuated Toxoplasma, rats vaccinated with gamma radiation-attenuated Toxocara canis larvae revealed a significant decrease in SOD and MDA with increase of GSH in kidney tissues compared to infected control group (43).

Regarding histopathological changes and histochemical expression of nuclear DNA, dilated central and portal veins with inflammatory cellular infiltrate were clearly observed in infected group. Furthermore, mild positivity for Feulgen's stain with marked reduction of DNA and loss of nuclear membrane in most of hepatocyte nuclei in peri-veinular area was also detected. It has been shown that free radicals from peroxidase in Kupffer cells play a predominant role in hepatic pathogenesis and the decrease in the levels of liver SOD may lead to excess superoxide radicals which may interact with hydrogen peroxides and organic peroxides with generation of highly reactive entities that can attack DNA (44).

In the present study, vaccinated group revealed an amelioration of these histopathological changes and increased expression of nuclear DNA in hepatocytes compared to infected group. This was in consistence with previous study by Amin and Hafez (2015) who reported minimal histopathological alterations with normal architecture of the hepatic lobules and minimal degeneration of nuclear DNA in mice vaccinated with either gamma or UV radiation-attenuated Toxoplasma. This was explained by the direct effect of radiations that weaken the parasites and induce changes leading to decreased or abolished reproduction by damaging of the DNA molecules. However irradiated parasite

Int. J. Radiat. Res., Vol. 19 No. 1, April 2021 
maintains viability, a respiratory response and preserved protein and nucleic acid synthesis so, it present antigens to the host's immune system and elicit cellular immunity and cytokine responses in a highly similar way to natural infection $(22,45)$.

In current study, an increasing level of TNF- $\alpha$ was recorded in infected group compared to normal one. This proapoptotic molecule and others as nitric oxide (NO) are produced by macrophages as a result of invasion with Toxoplasma parasite to maintain the viability of the cell during its residence (46). Also, an elevation of IL-10 level was detected which was in line with Mammari etal. (47) who reported that ROP16, a molecule secreted by rhoptries, stimulates IL-10 expression and induces activation of macrophages thus promoting Th-2 response. Likewise, previous studies reported a significant increase of TNF- $\alpha$ and IL-10 in T. gondii-infected patients compared with healthy control $(48,49)$.

On the other hand, vaccinated group showed a significant decrease of their levels compared to infected group and significant increase compared to normal control one which may be due to the immunogenic effect of living attenuated parasite that can be recognized as protein antigen. Similar results were recorded by Moawad et al. (16) who reported a significant decrease in serum levels of IL-10 and TNF- $\alpha$ in mice vaccinated with either UV or gamma-radiation attenuated Toxoplasma tachyzoites compared to infected control.

\section{CONCLUSION}

From the results obtained, it is concluded that gamma radiation-attenuated version of Toxoplasma that cannot replicate within the host exerts an alleviated oxidative stress activity. Furthermore, it induces immunomodulatory effects with significant decrease of promoting inflammatory cytokines. This was collimated with an amelioration of histopathological changes and DNA depletion in hepatocytes. Therefore, further studies are required to elucidate the beneficial effect of using selective radiation-attenuated non replicating vaccine to exclude the delirious effects of imposing infection by using live one.

\section{ACKNOWLEDGEMENTS}

The authors wish to acknowledge the assistance given by the National Center of Radiation, Research and Technology for providing all facilities needed to this study. Also, authors wish to acknowledge the assistance given by Professor Dr. Sayed Abdel Raheem, Associate professor of histopathology, Al-Azhar University.

Conflicts of interest: Declared none.

\section{REFERENCES}

1. Menegolla I, Difante C, Ramos L, Dorneles D, Streb A, Mello L, et al. (2018) Investigação de surto de toxoplasmose em Santa Maria/RS, 2018. In IV Simpósio Brasileiro de Toxoplasmose, Brazil.

2. Shapiro K, Bahia-Oliveira L, Dixon B, Dumètre A, DeWit LA, Wormer VE, Villena I (2019) Environmental transmission of Toxoplasma gondii: Oocysts in water, soil and food. Food and Waterborne Parasitol, 2: 1-17

3. MacRae JI, Sheiner L, Nahid A, Tonkin C, Striepen B, McConville MJ (2012) Mitochondrial metabolism of glucose and glutamine is required for intracellular growth of Toxoplasma gondii. Cell Host and Microbe, 12: 682-692.

4. Derda M, Wandurska-Nowak E, Hadas E (2004) Changes in the level of antioxidants in the blood from mice infected with Trichinella spiralis. Parasitol Res, 93: 207-210.

5. Gabrashanska M, Teodorova SE, Petkova S, Mihov L, Anisimova M, Ivanov D (2010) Selenium supplementation at low doses contributes to the antioxidant status in Trichinella spiralis-infected rats. Parasitol Res, 106: 561-570.

6. Almeer RS, Alarifi S, Alkahtani S, Ibrahim SR, Ali D, Moneim A (2018) The potential hepatoprotective effect of royal jelly against cadmium chloride-induced hepatotoxicity in mice is mediated by suppression of oxidative stress and upregulation of Nrf2 expression. Biomed Pharmacother, 106: 1490-1498.

7. Wang XN, Zhang CJ, Diao HL, Zhang Y (2017) Protective effects of curcumin against sodium arsenite-induced ovarian oxidative injury in a mouse model. Chinese Med J, 130 : 1026-1032.

8. Saada HN, Azab KS (2001): Role of lycopene in recovery of radiation induced injury to mammalian cellular organelles. Pharmazie, 56: 239-241. 


\section{Hazel et al. / Irradiated toxoplasma vaccine improves oxidative stress}

9. Yarovinsky F (2014) Innate immunity to Toxoplasma gondii infection. Nat Rev Immunol, 14: 109-21.

10. Nahrevanian $H$ (2009) Involvement of nitric oxide and its up/down stream molecules in the immunity against parasitic infections. Braz J Infect Dis, 13(6): 440-448.

11. Schlüter D, Deckert-Schlüter M, Lorenz E, Meyer T, Röllinghoff M, Bogdan C (1999) Inhibition of inducible nitric oxide synthase exacerbates chronic cerebral toxoplasmosis in Toxoplasma gondii-susceptible C57BL/6 mice but does not reactivate the latent disease in $T$. gondii-resistant BALB/C mice. J Immunol, 162(6): 3512-8.

12. Muñoz $M$, Heimesaat MM, Danker $K$, Struck $D$, Lohmann U, Plickert R, et al. (2009) Interleukin (IL)-23 mediates Toxoplasma gondii-induced immunopathology in the gut via matrixmetalloproteinase-2 and IL-22 but independent of IL-17. J Exp Med, 206(13): 3047-3059.

13. Lima TS, Melissa B, Lodoen MB (2019) Mechanisms of Human Innate Immune Evasion by Toxoplasma gondii. Front Cell Infect Microbiol, 9: 103.

14. Miller CM, Boulter NR, Ikin RJ, Smith NC (2009) The immunobiology of the innate response to Toxoplasma gondii. Int J Parasitol, 39: 23-39.

15. Vossenkamper A, Struck D, Esquivel CA, Went T, Takeda K Akira S, Pfeffer K, Alber G, Lochner M, Forster I, Liesenfeld O (2004) Both IL-12 and IL-18 contribute to small intestinal Th1-type immunopathology following oral infection with Toxoplasma gondii, but IL-12 is dominant over IL-18 in parasite control. Euro J Immunol, 34(11): 3197-3207.

16. Moawad MA, Amin MM, Hafez EN (2016) Vaccination with irradiated tachyzoites show better therapeutic effect than some plants or drugs on toxoplasmosis. Pakist J Zoolo, $\mathbf{4 8}$ (1): 241-248.

17. Chen $M$, Aosai $F$, Norose $K$, Mun $H$, Ishikura $H$, Hirose $\mathrm{S}$, Piao L, Fang H, Yano A (2004) Toxoplasma gondii infection inhibits the development of lupus-like syndrome in autoimmune (New Zealand Black $\times$ New Zealand White) F1 mice. Int Immunol, 16: 937-946.

18. Washino T, Moroda M, Iwakura Y, Aosai F (2012) Toxoplasma gondii Infection Inhibits Th17-Mediated Spontaneous Development of Arthritis in Interleukin-1 Receptor Antagonist-Deficient Mice. Infect immune, 80(4): 14371444.

19. Hibbs JB, Lewis H, Lambert LH, Remington JS (1971) Resistance to murine tumors conferred by chronic infection with intracellular protozoa, Toxoplasma gondii and Besnoitia jellisoni. J Infect Dis, 124: 587-592.

20. Kim J, Jung S, Kim S, Kim TY, Shin D, Lee J, Lee Y (2007) Inhibition of Lewis Lung Carcinoma Growth by Toxoplasma gondii through Induction of Th1 Immune Responses and Inhibition of Angiogenesis. J Korean Med Sci, 22: S38-S46.

21. Rankin EB, Yu D, Jiang J, Shen $H$, Pearce EJ, Goldschmidt $\mathrm{MH}$, Levy DE, Golovkina TV, Hunter CA, ThomasTikhonenko A (2003) An essential role of Th1 responses and interferon $\mathrm{g}$ in infection-mediated suppression of neoplastic growth. Cancer Biol Ther, 2: 687-693.

22. Amin MM and Hafez EN (2015) Ultrastructure of toxoplasma gondii RH tachyzoites attenuated by gamma radiation and histopathological alterations in mice vaccinated with it. Pakistan J Zoolo, 47(5): 1325-1333.

23. Yeo SJ, Jin CM, Kim SY, Park H (2016) In vitro and in vivo effects of nitrofurantoin on experimental toxoplasmosis. Korean J Parasitol, 54: 155-161.

24. Hafez EN, Hanan MG, Youssef HMG, El-Kabany HA (2020) Vaccination with gamma radiation-attenuated Toxoplasma gondii protects against ovarian infiltration in mice-bearing Ehrlich ascites carcinoma. Inter J Rad Biol, 96(6): 814-822.

25. Atmaca HT, Kul O, Karakuş E, Terzi OS, Canpolat S, Anteplioğlu T (2014) Astrocytes, microglia/macrophages, and neurons expressing Toll-like receptor 11 contribute to innate immunity against encephalitic Toxoplasma gondii infection. Neuroscience, 269: 184-191.

26. El Gawish MAM, Moawad MAF, Mahmoud NFA (2001) Trial to use Irradiated Cysts as a Vaccine Against Toxoplasma Gondii Infection in Rats. Arab J Nucl Sci Appli, 34(2): 223-228.

27. MacManus JFA and Mowry RW (1964) Staining: Histological and histochemical. 1st ed. Harper and Row, New York, USA, 74: 126.

28. Kiernan JA (1981) Histological and histochemical methods: Theory and practice. 1st ed Oxford; New York: Pergamon Press, - International Library of Science, Technology, Engineering, and Social Studies, pp. 400.

29. Ohkawa H, Ohishi N, Yagi K (1979) Assay for lipid peroxides in animal tissues by thiobarbituric acid reaction. Anal Bio-chem, 95: 351-358.

30. Sun Y, Oberley LW, Li YA (1988) Simple method for clinical assay of superoxide dismutase. Clin Chem, 34: 497-500.

31. Beutler E, Duron O, Kelly BM (1963) Improved method of the determination of blood glutathione. J Lab Clin Med, 61: 882-888.

32. Sutterwala F, Noel G, Salgane P, Mosser D (1998) Reversal of proinflammatory response by ligating the macrophage Fc gamma receptor Type I. J Exp Med, 188: 217-222.

33. Delavari I, Khadjeh G, Bahrami S, Jalali SM, Esmaeelzadeh $S$ (2017) Evaluation of Local tissue oxidative stress and its possible involvement in the pathogenesis of toxoplasmosis in rats experimentally infected with Toxoplasma gondii. Trop Biomed, 34(3): 708-716.

34. Al-Kennany ER (2007) Pathological study on the capability of Toxoplasma gondii to induce oxidative stress and initiation a primary lesion of atherosclerosis experimentally in broiler chickens. J Ani Vet Advan, 6: 938-942.

35. Xu X, Liu T, Zhang A, Huo X, Luo Q, Chen Z, Shen J (2012) Reactive oxygen species-triggered trophoblast apoptosis is initiated by endoplasmic reticulum stress via activation of caspase-12, CHOP, and the JNK pathway in Toxoplasma gondii infection in mice. Infect Immuol, 80: 2121-2132.

36. Türkoğlu ŞA, Yaman K, Orallar H, Camsari C, Karabörk Ş, Ayaz E (2018) Acute toxoplasmosis and antioxidant levels in the liver, kidney and brain of rats. Ann Parasitol, 64(3): 241-247.

37. De Oliveira RB, Vasques LM, Senger MR, Gelain DP (2013) Schistosoma mansoni infection causes oxidative stress and alters receptor for advanced glycation endproduct (RAGE) 
and tau levels in multiple organs in mice. Int J Parasitol, 43: 371-379.

38. Gabrashanska M, Petkova S, Teodorova SE, Ivanov D (2010) Selenium supplementation at low doses contributes to the antioxidant status in Trichinella spiralisinfected rats. Parasitol Res, 106: 561-570.

39. Novaes RD, Santyos EC, Cupertino MC, Bastos DS, Oliveira JM, Carvalho TV, Neves MM, Oliveira LL, Talvani A (2015) Trypanosoma cruzi infection and benznidazole therapy independently stimulate oxidative status and structural pathological remodeling of the liver tissue in mice. Parasitol Res, 114: 2873-2881.

40. Dincel GC, Atmaca HT(2015) Nitric oxide production increases during Toxoplasma gondii encephalitis in mice. Exp Parasitol, 156: 104-12.

41. Bando H, Lee Y, Sakaguchi N, Pradipta A, Ma SJ, Tanaka S, Cai Y, Liu J, Shen J, Nishikawa Y, Sasai M, Yamamoto M (2018) Inducible Nitric Oxide Synthase Is a Key Host Factor for Toxoplasma GRA15-Dependent Disruption of the Gamma Interferon-Induced Antiparasitic Human Response. Amer soci microbial, IDOI: 10.1128/mBio.01738-18.

42. Alajmi RA, AL-Megrin WA, Metwally D, AL-Subaie H, Altamrah N, Barakat AM, Abdel Moneim AE, Al-Otaibi TT, I El-Khadragy M (2019) Anti-toxoplasma activity of silver nanoparticles green synthesized with Phoenix dactylifera and Ziziphus spina-christi extracts which inhibits inflammation through liver regulation of cytokines in Balb/c mice. Biosci Rep 31; 39(5): doi: 10.1042/BSR20190379

43. Moawad MA, Amin MM, Hafez EN (2015) Role of ionizing radiation on controlling kidney changes in experimental infection with Toxocara canis. Assiut Vet Med J, 61(147): 87-94.

44. Kono H, Rusyn I, Yin M, Gaebele E, Yamashina S, Dikalova A, Kadiiska M, Connor H, Mason R, Segal B, Bradford B, Holland S, Thurman R (2000) NADPH oxidase-derived free radicals are key oxidants in alcohol-induced liver disease. $J$ Clin Invest, 106: 867-872.

45. Hiramoto RM, Galisteo J, Nascimento ND, Andrade J (2002) Tachyzoites of Toxoplasma gondii irradiated with $255 \mathrm{~Gy}$ induces decrease of cysts and cerebral lesions in mice challenged with cyst ME-49 [Instituto de Pesquisas Energeticas e Nucleares (IPEN), Sao Paulo, SP (Brazil). Lab. de Biologia Molecular, 33: 46.

46. Tomita T, Yamada T, Weiss LM, Orlofsky A (2009) Externally triggered egress is the major fate of Toxoplasma gondii during acute infection. J Immunol, 183(10): 6667-6680.

47. Mammari, N, Halabi MA, Yaacoub, S., Chlala H, Dardé, M, Courtioux B (2019) Toxoplasma gondii Modulates the Host Cell Responses: An Overview of Apoptosis Pathways. Bio Med Res Int, Volume 2019, Article ID 6152489, 10 pageshttps://doi.org/10.1155/2019/6152489

48. Olaniyan MF, Afolabi T, Idume NO (2019) Relationship between parasitic infection of Toxoplasma gondii, IL-2, TNF- $\alpha$ tryptophan and CD4+ count. J Nat Sci Med, 2: 64-8.

49. Mohamed KIA, Khadhum MS, Abu-Al- Ess HQM, Ali SHM, Al-Fukhar SA, Al-Wattar WMA,. Hamoudi SR, Mousa JM (2017) The Effect of Toxoplasma gondii on Interleukin-8, Interleukin-10, Leukotriene B4 and Calcium Levels in Aborted Women. Int J Med Res Heal Sci, 6(11): 76-82. 
